\title{
Elaboration and Validation of Flowchart for the Prevention and Treatment of Intestinal Peristomal Skin Complications
}

\author{
Imaculada Aparecida Cardoso ${ }^{10}$ Geraldo Magela Salomé ${ }^{10}$

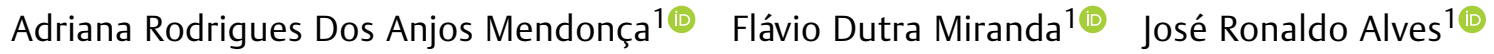 \\ ${ }^{1}$ Programa de Mestrado Profissional em Ciências Aplicadas à Saúde, \\ Address for correspondence Geraldo Magela Salomé, RN, PhD, \\ Universidade do Vale do Sapucaí, São Paulo, SP, Brazil \\ Sapucaí Valley University - UNIVÀS, São Paulo, SP 04330-020, Brazil \\ (e-mail: salomereiki@yahoo.com.br).
} J Coloproctol 2021;41(3):316-324.

\begin{abstract}
Objective To build and validate a flowchart for the prevention and treatment of intestinal peristomal skin complications.

Method For the construction of the algorithms, a systematic review was carried out in health sciences databases comprising the last 10 years. The evaluation of the algorithms was carried out by 38 nurses. For the validation of the algorithms, the Delphi technique was used. The statistical analysis used was the content validity index and the Cronbach alpha coefficient. The questionnaire was sent by e-mail and in person after approval by the Ethics and Research Committee.

Results In the first evaluation of the algorithms, there was no agreement among the experts. However, after making the corrections suggested by the evaluators, the algorithms were resent, with a $100 \%$ consensus among the evaluators. The questions used to validate the algorithms contributed favourably to the internal consistency and content validation of the instrument, since the respective Cronbach alpha was 0.9062

\section{Keywords}

- stoma

- dermatitis

- algorithms

- mobile apps and the global content validity index ( $\mathrm{g}-\mathrm{CVI}$ ) was 0.91 in the first validation and 1.0 in the second validation.

Conclusion After an integrative literature review, the flowcharts were built and validated by a professional with experience in the area, showing $100 \%$ agreement among the experts in the second evaluation.
\end{abstract}

\section{Introduction}

In the $21^{\text {st }}$ century, sociodemographic, economic, and epidemiological changes caused by accelerated urbanization, new consumption patterns, globalization of knowledge, scientific and technological advances have had a major national impact, with a decline in the birth rate, increased life expectancy, and, consequently, of longevity associated in parallel with the increase of chronic noncommunicable diseases, a high number of traffic accidents, and an increase in urban violence, resulting in a growing increase in the number of people with stomas in Brazil. Approximately 1.4 million stoma-making surgical procedures are performed every year. ${ }^{1}$ received

August 25, 2020

accepted

January 15, 2021
DOI https://doi.org/

10.1055/s-0041-1735460.

ISSN 2237-9363.

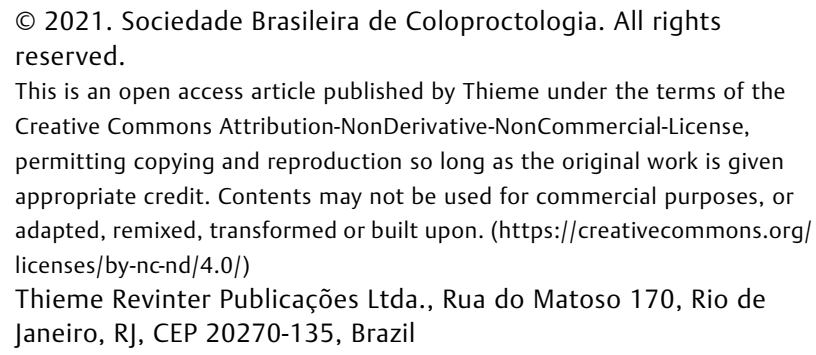

This is an open access article published by Thieme under the terms of the Creative Commons Attribution-NonDerivative-NonCommercial-License, permitting copying and reproduction so long as the original work is given appropriate credit. Contents may not be used for commercial purposes, or adapted, remixed, transformed or built upon. (https://creativecommons.org/ licenses/by-nc-nd/4.0/)

Thieme Revinter Publicações Ltda., Rua do Matoso 170, Rio de Janeiro, RJ, CEP 20270-135, Brazil 
The purpose of this surgery is the diversion of the contents of the intestine (gases and faeces) to an external bag. ${ }^{2}$ This procedure is carried out so that the elimination function is maintained, and it causes several changes, among which can be highlighted the elimination of gases, odour and faeces by the stoma located in the abdominal wall.

According to the 2010 census of the Brazilian Institute of Geography and Statistics, when the total population of Brazil was 190,732,694 people, it was estimated that there were $\sim$ 190,000 ostomy patients in Brazil, and 120,000 stoma creation surgeries annually in the United States. ${ }^{3}$

Between 21 and $70 \%$ of ostomized patients develop some type of complication, although a significant percentage of these patients could live with the stoma without complications. These complications are related to the malfunction of the ostomy, to demarcation in an incorrect anatomical region, and to the difficulty of the patient in performing self-care. ${ }^{4}$ Such complications can lead to dermatitis, bleeding, prolapse, necrosis, hernias, edema, waste leakage, peristomal hernia, stenosis, and retraction, among other adversities. $^{5-11}$

Nurses have a great responsibility in the care of the ostomate, since they participate in all stages of care. In the preoperative period, it is recommended that the stoma location be demarcated by the stoma nurse, starting to teach the patient and family about the surgery and its consequences, as well as identifying other learning needs. In the postoperative period, self-care teaching is resumed in relation to the stoma, indication and replacement of equipment, and the patient is prepared for hospital discharge. $9,12-15$

Health professionals who provide assistance to ostomized patients should always seek new knowledge, as scientific updates and advances in technologies related to the care of intestinal peristomal skin are constantly evolving. It is not difficult to find professionals who work in the hospital and outpatient setting who have difficulties in carrying out the exchange of the bag, in hygienizing the intestinal peristomal skin, in identifying the ideal bag for each patient, and in identifying the type of stoma. In addition, the evaluation of a stoma can lead to different interpretations due to its diversity in terms of nature, shape and location, depending on each professional's own perception and technical knowledge, considering the subjective factors of the evaluation. ${ }^{16-19}$

Algorithms are technologies that guide decision-making in the face of clinical care issues, add scientific rationality, and serve as guides for self-care, prevention and treatment of peristomal skin complications. They provide information about the best prophylactic-therapeutic conduct to be adopted in each clinical evaluation made by the nursing and multiprofessional team, which confirms its proficiency and accuracy as a guiding instrument of care. The elaboration and structuring of the algorithm must be composed by the evaluation of the algorithm by a professional with knowledge in the area, care actions, and therapeutic proposal. ${ }^{17-20}$

Thus, it was essential to develop protocols in the form of algorithms that make the clinical management of ostomy patients more effective, as well as minimizing difficulties and deficiencies of the nurses in relation to clinical practice. With this, it is expected to contribute to the dissemination of knowledge about the evaluation of intestinal peristomal skin, promoting the health of this population, as well as assisting professionals in the elaboration of preventive actions, therapeutic conduct, and health education actions.

The present study aimed to build and validate flowcharts for the prevention and treatment of intestinal peristomal skin complications.

\section{Methods}

A methodological study on the development of a technological application.

For the elaboration of the algorithms, an integrative literature review was carried out in the following health sciences databases: Scientific Electronic Library Online (SciELO), Latin American and Caribbean Literature in Health Science (LILACS), and National Library of Medicine - USA (MEDLINE). For the search, the descriptors stoma and dermatitis were used.

For the selection of publications, the following inclusion criteria were adopted: only primary studies that had a direct connection with the theme; full text available and no time limitation proposed, as the intention was to compile all studies that met the established criteria. The following were excluded: book chapters, theses, dissertations, monographs, technical reports, reference works, and articles that, after reading the abstract, did not converge with the proposed study object.

The articles were classified according to the level of evidence in: 1 , when the evidence came from a systematic review or meta-analysis of all randomized controlled clinical trials, relevant or derived from clinical guidelines based on systematic reviews of randomized controlled clinical trials; 2 , if the evidence was derived from at least one well-designed randomized controlled clinical trial; 3 , when the evidence was obtained from well-designed clinical trials without randomization; 4, evidence from cohort and well-designed case control studies; 5 , evidence from a systematic review of descriptive and qualitative studies; 6 , evidence derived from a single descriptive or qualitative study; 7 , evidence originating from the opinion of authorities and/or the report of expert committees. ${ }^{21}$

After reading the abstracts, articles that described the following subjects were selected: evaluation of intestinal peristomal skin, care of intestinal peristomal skin, prevention of intestinal peristomal skin, and treatment of complications of intestinal peristomal skin. From this survey, the algorithms for the prevention and treatment of intestinal peristomal skin complications were developed in three stages.

\section{First stage: Construction of the Flowcharts for the Prevention of Intestinal Peristomal Skin Injuries}

First step - In this phase, a standardization was elaborated to carry out anamnesis and physical examination. 
Second step - At this stage, a plan was developed with preventive measures and actions for self-care, in case the patient does not present signs and symptoms of complications in the intestinal peristomal skin.

\section{Second Stage: Elaboration of Flowcharts for the Treatment of Intestinal Peristomal Skin Complications}

First step: At this stage, the types of dermatitis were classified, exposing signs and symptoms present in each type of dermatitis and its causes based on the reviewed literature.

Second step: Standardization of therapeutic approaches to each dermatitis: at this stage, a plan of therapeutic approaches based on the reviewed literature for each type of dermatitis found was developed.

\section{Third Stage: Validation of the Algorithms}

The present study was carried out at the Hospital das Clínicas Samuel Libânio, at the Universidade do Vale do Sapucaí, São Paulo, state of São Paulo, Brazil. The study population consisted of 38 nurses. The study was approved by the Research Ethics Committee of the Faculty of Medical Sciences Dr. José Antônio Garcia Coutinho of the Universidade do Vale do Sapucaí, under the consubstantiated opinion number 2.557.232.

The inclusion criteria of the evaluators were: to be a professional holding a certificate of an undergraduate nursing course, with at least 1 year of experience in treating patients with skin lesions. The exclusion criteria were professionals who agreed to participate in the research but did not answer neither/nor submitted the evaluation questionnaire within 15 days.

For the validation of the algorithms, the following documents were elaborated and sent to the research participants:

The invitation letter, which was composed of: initial personal presentation and clarifications on the research topic, with an objective definition regarding the ostomy, opinion of the Research Ethics Committee of the Faculty of Health Sciences Dr. José Antônio Garcia Coutinho, and explanations about the importance of the professional evaluator in the research. The step by step for the effective participation of the evaluators, as well as the period of 15 days for each evaluation round, counting from the day of delivery, to elaborate and forward the answers, were also included in the letter.

The informed consent form (ICF) made the content of the research clear to the evaluator, guaranteeing the confidentiality of personal information and their free decision whether or not to participate in it, in addition to the knowledge of the right to withdraw, at any time, their consent to participate in the research. In that term, in case of acceptance, name and profession of the participant were requested.

The professionals evaluated the following items of the algorithms: thematic content, graphic presentation, vocabulary, sequence, clarity and understanding of the information, description of the physical examination and anamnesis of the peristomal skin, description of the peristomal skin care, peristomal skin cleaning technique, and replacement of pouching systems of one and two pieces, classification of dermatitis, its causes, signs, and symptoms, and appropriate therapeutic procedures, when evidenced.

The Likert scale was used in the questions to evaluate the algorithms, with the following answer options: "appropriate", "totally appropriate", "not appropriate", "partially appropriate", and "not applicable". In all items, there was room so that the participants could insert their own opinions and suggestions.

The process of validating the algorithms went as follows:

1. Selection of professional evaluators: the e-mails or personal contacts of the research participants registered in the institutions mentioned above were verified.

2. Sending the instrument to the evaluators by e-mail in a simple way, as an attachment, or delivered by hand in printed form. The participants read and signed the ICF. Freely agreeing to participate in the survey, they provided their full name, profession, and individual taxpayer registration (CPF, in the Portuguese acronym). Those who received the instrument electronically, printed, signed, replied, scanned and sent it.

3. In the analysis of the data, the answers marked with classification 3 (appropriate) or 4 (totally appropriate) were considered valid. Responses rated 1 (inappropriate) or 2 (partially appropriate) were not excluded. The suggestions made by the experts were evaluated and revisions were made so that the items were considered validated, and these guidelines were indicated in previous studies on this evaluation method. ${ }^{23}$ Questions that received ratings 1 (inappropriate) or 2 (partially appropriate) were sent to the participants in the second round of evaluation with suggestions made for a new round, reaching a consensus of $100 \%$ of approval among the evaluators; this type of procedure is known as the Delphi technique.

The Delphi technique is a method that obtains opinions from evaluators with specific knowledge in a certain area. The Delphi technique uses questionnaires whose contents are analysed and judged by specialists seeking a $100 \%$ consensus among the evaluators. Generally, there are two to three rounds or evaluation cycles, but there may be more. ${ }^{23}$

This is a result counting technique depending on the degree of expertise, without specifying the number of judges. This technique motivates the evaluators to think more about the subject, as they will be the creators of the theme in question. For this process, two groups were used: an executor group, which was composed by the researchers, whose function was to contact the respondents, to prepare the initial questionnaire, to analyse the data, and to elaborate the other questionnaires; and the group formed by the selected experts. ${ }^{24}$

The obtained data were electronically tabulated with the aid of Microsoft Excel 2010 (Microsoft Corporation, Redmond, WA, USA) and were subsequently analysed quantitatively using the same program.

The data were analysed and correlated to determine the Cronbach alpha coefficient, which aims to estimate the 
reliability of the instrument. The higher the covariance or correlation between the items, that is, the closer the value obtained is to one, the greater the homogeneity of the items and the consistency with which they measure the same dimension or theoretical construct. A Cronbach's alpha coefficient $>0.7$ indicates a good internal consistency of the instrument.

To validate the content of the algorithms, the content validity index (CVI) was used, whose purpose was to measure the proportion or percentage of participants who agree on certain aspects of the instrument and its items. The CVI is a widely used method in the health field. The CVI uses a Likert scale with a certain number of points for concordance and representativeness. Answers may vary, for example, from relevant to unrepresentative, or from clear to unclear. ${ }^{25}$ For the present study, the questionnaire contained 5 alternative answers with an answer for each question, as follows: $1=$ Inappropriate (I); 2 = Partially Appropriate (PA); $3=$ Appropriate (A); $4=$ Totally Appropriate (TA). In all items, there was room so that the experts could insert their own opinions and suggestions.

For validation, a quantitative assessment was carried out item by item in the questionnaire. The CVI was calculated considering the number of responses "3" (Appropriate) or " 4 " (Totally Appropriate) for each item divided by the total number of responses. The value of the CVI for the validation of a questionnaire must be $\geq 0.78$, when there is the participation of $\geq 6$ validation specialists. ${ }^{25}$

For the validation of the instrument as a whole, there is no consensus between the different formulas. In the present study, we chose to use the following calculation: the sum of all CVIs of each item calculated separately divided by the number of items that were considered in the questionnaire evaluation, with a minimum mandatory agreement $>0.90 .^{25}$

\section{Results}

- Table 1 shows the evaluation of the algorithms using the Delphi technique. In the first evaluation, the experts evaluated each question of the algorithms between inappropriate and totally appropriate; however, in the second evaluation, the algorithms obtained the evaluation of appropriate and totally appropriate.

- Table 2 shows that the mean Cronbach alpha was 0.9062 . By relating the questions of the algorithms to $\alpha$, it varied from 0.8916 to 0.9100 , characterizing that the questions contained in the algorithms have excellent internal reliability.

- Table 3 makes it possible to observe that, in the first evaluation, the CVI of the questions varied between 0.89 and 0.97 and that the g-CVI was 0.91. After the corrections requested by the participants, the algorithms were revaluated, with the CVI of all questions being 1.0 and the global content validity index (g-CVI) was 1.0. These results demonstrate that the experts agree regarding the content of the algorithms.

\section{Discussion}

The descriptive protocols or in form of algorithms must be developed based on scientific evidence, as they have the purpose of guiding professionals, patients, companions, and caregivers in decision-making so that they provide care free of damages, adverse events, and with minimum possible risk. ${ }^{17,18,26}$

The present study built two algorithms (-Figures 1 and 2) that will serve as a clinical tool in decision-making in the assessment, prevention and therapeutic approaches related to intestinal peristomal skin complications.

The use of protocols in algorithm format in clinical practice contributes to the individualized registration of care and systematic assessment, enabling the continuity of preventive measures and of the treatment, and promoting the quality of care. The algorithms must be built on a scientific basis and after a review of the literature on the topic. ${ }^{27}$ The systematic evaluation of the peristomal skin minimizes the healing time and allows analysis of the costs and benefits of the treatment used. ${ }^{17}$

The construction of an algorithm for the evaluation of injuries must be strongly based on the literature and on clinical evidence to provide technological, technical, clinical, administrative, and financial subsidies, always aiming at improving patient care and at the best results for the institution. $^{17-19}$

The content of the algorithms developed in the present research was evaluated by nurses using the Delphi technique. In the first evaluation, most of the evaluators considered the content of the algorithms as inappropriate to appropriate. However, after making the corrections that were suggested by the evaluators, the algorithms were evaluated as appropriate to totally appropriate, with a Cronbach alpha of 0.9062 . These findings characterize that the questionnaire used to validate the content of the algorithms has good internal consistency and excellent reliability, corroborating the findings of other authors. ${ }^{17-19,25}$

Several studies that validated the content of the protocols, booklets, apps, and algorithms using the Delphi technique report that the corrections suggested by the evaluators must be made on a scientific basis, as they contribute to a better understanding, effectiveness, and implantation of the material in the institution, allowing the professional to choose the best preventive measure and therapeutic approaches, resulting in safe assistance, without damage and with the least possible risk and reduction in the cost of treatment. ${ }^{17-19,28}$

Regarding the validation of the content of the algorithms, in the first evaluation, the g-CVI was 0.91 and, in the second evaluation, the g-CVI was 1.0. These results demonstrate agreement among the experts only in the second evaluation, and they coincide with the results found by other authors. ${ }^{17-19,28}$

Protocols, algorithms, booklets, manuals, flowcharts, and guidelines are considered important tools for coping with various problems in the care and management of health services. Studies validated by scientific evidence are based on guidelines of a technical, organizational, and political nature. 
Table 1 Evaluation of the content of the items of the algorithms for the prevention and treatment of peristomal skin complications using the Delphi technique. Pouso Alegre, MG, Brasil, 2019

\begin{tabular}{|c|c|c|c|c|c|c|c|c|c|c|}
\hline \multicolumn{11}{|l|}{ Delphi Technique } \\
\hline \multicolumn{11}{|l|}{ First evaluation } \\
\hline \multirow[t]{2}{*}{ Questions } & \multicolumn{2}{|c|}{$\begin{array}{l}\text { Inap- } \\
\text { propriate }\end{array}$} & \multicolumn{2}{|c|}{$\begin{array}{l}\text { Partially } \\
\text { appropriate }\end{array}$} & \multicolumn{2}{|c|}{ Appropriate } & \multicolumn{2}{|c|}{$\begin{array}{l}\text { Totally } \\
\text { appropriate }\end{array}$} & \multicolumn{2}{|l|}{ Total } \\
\hline & $n$ & $\%$ & $n$ & $\%$ & $n$ & $\%$ & $n$ & $\%$ & $N$ & $\%$ \\
\hline Regarding Algorithm's design & 00 & 00 & 03 & 07.90 & 16 & 42.10 & 19 & 50 & 38 & 100 \\
\hline Regarding Algorithm's content & 00 & 00 & 03 & 07.90 & 14 & 36.80 & 21 & 55.30 & 38 & 100 \\
\hline Regarding Algorithm's sequence & 00 & 00 & 04 & 10.50 & 10 & 26.30 & 24 & 63.20 & 38 & 100 \\
\hline Regarding Algorithm's vocabulary & 00 & 00 & 03 & 07.90 & 11 & 28.90 & 24 & 63.2 & 38 & 100 \\
\hline Regarding the understanding of the Algorithm information & 00 & 00 & 03 & 07.90 & 10 & 26.30 & 25 & 65.80 & 38 & 100 \\
\hline $\begin{array}{l}\text { Regarding the description of the physical examination and } \\
\text { anamnesis of the peristomal skin }\end{array}$ & 00 & 00 & 03 & 07.90 & 15 & 39.50 & 20 & 52.60 & 38 & 100 \\
\hline Regarding the description of skin care around the stoma & 00 & 00 & 05 & 13.20 & 08 & 21.00 & 25 & 65.80 & 38 & 100 \\
\hline Regarding the technique for cleaning peristomal skin & 01 & 2.60 & 04 & 10.50 & 12 & 31.60 & 21 & 55.30 & 38 & 100 \\
\hline $\begin{array}{l}\text { Regarding the description of the technique of changing an } \\
\text { one-part pouching system }\end{array}$ & 01 & 2.60 & 04 & 10.50 & 12 & 31.60 & 21 & 55.30 & 38 & 100 \\
\hline $\begin{array}{l}\text { Regarding the description of the technique of changing a } \\
\text { two-part pouching system }\end{array}$ & 00 & 00 & 00 & 01 & 02.60 & 16 & 42.10 & 21 & 55.30 & 38 \\
\hline Regarding dermatitis classification & 00 & 00 & 01 & 02.60 & 16 & 42.10 & 21 & 55.30 & 38 & 100 \\
\hline Regarding the description of the causes of dermatitis & 00 & 00 & 02 & 05.30 & 14 & 36.80 & 22 & 57.90 & 38 & 100 \\
\hline $\begin{array}{l}\text { Regarding the description of the signs and symptoms of } \\
\text { dermatitis }\end{array}$ & 01 & 2.6 & 03 & 07.90 & 10 & 26.30 & 24 & 63.20 & 38 & 100 \\
\hline Regarding the description of therapeutic approaches & 00 & 00 & 004 & 10.50 & 18 & 47.40 & 16 & 42.10 & 38 & 100 \\
\hline \multicolumn{11}{|l|}{ Delphi Technique } \\
\hline \multicolumn{11}{|l|}{ Second evaluation } \\
\hline \multirow[t]{2}{*}{ Questions } & \multicolumn{2}{|c|}{$\begin{array}{l}\text { Inappro- } \\
\text { priate }\end{array}$} & \multicolumn{2}{|c|}{$\begin{array}{l}\text { Partially } \\
\text { appropriate }\end{array}$} & \multicolumn{2}{|c|}{ Appropriate } & \multicolumn{2}{|c|}{$\begin{array}{l}\text { Totally } \\
\text { appropriate }\end{array}$} & \multicolumn{2}{|l|}{ Total } \\
\hline & $n$ & $\%$ & $n$ & $\%$ & $n$ & $\%$ & $n$ & $\%$ & $n$ & $\%$ \\
\hline Regarding Algorithm's design & 00 & 00 & 00 & 00 & 13 & 34.20 & 25 & 65.80 & 38 & 100 \\
\hline Regarding Algorithm's content & 00 & 00 & 00 & 00 & 08 & 21.10 & 30 & 78.90 & 38 & 100 \\
\hline Regarding Algorithm's sequence & 00 & 00 & 00 & 00 & 09 & 23.70 & 29 & 76.30 & 38 & 100 \\
\hline Regarding Algorithm's vocabulary & 00 & 00 & 00 & 00 & 09 & 23.70 & 29 & 76.30 & 38 & 100 \\
\hline Regarding the understanding of the Algorithm information & 00 & 00 & 00 & 00 & 08 & 21.10 & 30 & 78.90 & 38 & 100 \\
\hline $\begin{array}{l}\text { Regarding the description of the physical examination and } \\
\text { anamnesis of the peristomal skin }\end{array}$ & 00 & 00 & 00 & 00 & 11 & 28.90 & 27 & 71.10 & 38 & 100 \\
\hline Regarding the description of skin care around the stoma & 00 & 00 & 00 & 00 & 05 & 13.20 & 33 & 86.80 & 38 & 100 \\
\hline Regarding the technique for cleaning peristomal skin & 00 & 00 & 00 & 00 & 08 & 21.10 & 30 & 78.90 & 38 & 100 \\
\hline $\begin{array}{l}\text { Regarding the description of the technique of changing an } \\
\text { one-part pouching system }\end{array}$ & 00 & 00 & 00 & 00 & 10 & 26.30 & 28 & 73.70 & 38 & 100 \\
\hline $\begin{array}{l}\text { Regarding the description of the technique of changing a } \\
\text { two-part pouching system }\end{array}$ & 00 & 00 & 00 & 00 & 10 & 26.30 & 28 & 73.70 & 38 & 100 \\
\hline Regarding dermatitis classification & 00 & 00 & 00 & 00 & 09 & 23.70 & 29 & 76.30 & 38 & 100 \\
\hline Regarding the description of the causes of dermatitis & 00 & 00 & 00 & 00 & 09 & 23.70 & 29 & 76.30 & 38 & 100 \\
\hline $\begin{array}{l}\text { Regarding the description of the signs and symptoms of } \\
\text { dermatitis }\end{array}$ & 00 & 00 & 00 & 00 & 08 & 21.10 & 30 & 78.90 & 38 & 100 \\
\hline Regarding the description of therapeutic approaches & 00 & 00 & 00 & 00 & 10 & 26.30 & 28 & 73.70 & 38 & 100 \\
\hline
\end{tabular}

They also focus on the standardization of clinical, surgical, and preventive procedures. ${ }^{27,29-32}$

The algorithms developed in the present study provide relevant information about the best therapeutic and preven- tive direction to be adopted, guiding health professionals more safely in the evaluation and decision-making process before the ostomate who needs the intervention to prevent and treat intestinal peristomal skin complications, which 
Table 2 Internal consistency of items related to the algorithms. Pouso Alegre, MG, Brasil, 2019

\begin{tabular}{|l|c|}
\hline Questions presented in the algorithm validation questionnaire & Cronbach alpha \\
\hline Regarding Algorithm's design & ${ }^{*} 0.9089$ \\
\hline Regarding Algorithm's content & ${ }^{*} 0.9073$ \\
\hline Regarding Algorithm's sequence & ${ }^{*} 0.8937$ \\
\hline Regarding Algorithm's vocabulary & ${ }^{*} 0.9059$ \\
\hline Regarding the understanding of the algorithm information & ${ }^{*} 0.9100$ \\
\hline Regarding the description of the physical examination and anamnesis of the peristomal skin & ${ }^{*} 0.90140$ \\
\hline Regarding the description of skin care around the stoma & ${ }^{*} 0.8996$ \\
\hline Regarding the technique for cleaning peristomal skin & ${ }^{*} 0.8940$ \\
\hline Regarding the description of the technique of changing an one-part pouching system & ${ }^{*} 0.8916$ \\
\hline Regarding the description of the technique of changing a two-part pouching system & ${ }^{*} 0.8994$ \\
\hline Regarding dermatitis classification & ${ }^{*} 0.8943$ \\
\hline Regarding the description of the causes of dermatitis & ${ }^{*} 0.8933$ \\
\hline Regarding the description of the signs and symptoms of dermatitis & ${ }^{*} 0.8953$ \\
\hline Regarding the description of therapeutic approaches & ${ }^{*} 0.8977$ \\
\hline Cronbach alpha coefficient & ${ }^{*} 0.9062$ \\
\hline
\end{tabular}

Cronbach alpha test. * Significance level $\alpha>0.800$.

Table 3 Content validity index of the questions presented in the algorithms for the prevention and treatment of peristomal skin complications by the research participants. Pouso Alegre, MG, Brasil, 2019

\begin{tabular}{|c|c|c|}
\hline \multirow[t]{2}{*}{ Questions } & \multicolumn{2}{|l|}{ Content Validity Index } \\
\hline & CVI before correction & CVI after correction \\
\hline Regarding Algorithm's design & ${ }^{*} 0.92$ & $* 1.0$ \\
\hline Regarding Algorithm's content & ${ }^{*} 0.92$ & ${ }^{*} 1.0$ \\
\hline Regarding Algorithm's sequence & ${ }^{*} 0.89$ & $* 1.0$ \\
\hline Regarding Algorithm's vocabulary & ${ }^{*} 0.92$ & ${ }^{*} 1.0$ \\
\hline $\begin{array}{l}\text { Regarding the understanding of the algorithm } \\
\text { information }\end{array}$ & ${ }^{*} 0.92$ & ${ }^{*} 1.0$ \\
\hline $\begin{array}{l}\text { Regarding the description of the physical examination } \\
\text { and anamnesis of the peristomal skin }\end{array}$ & ${ }^{*} 0.92$ & ${ }^{*} 1.0$ \\
\hline $\begin{array}{l}\text { Regarding the description of skin care around the } \\
\text { stoma }\end{array}$ & ${ }^{*} 0.87$ & ${ }^{*} 1.0$ \\
\hline Regarding the technique for cleaning peristomal skin & ${ }^{*} 0.87$ & ${ }^{*} 1.0$ \\
\hline $\begin{array}{l}\text { Regarding the description of the technique of changing } \\
\text { an one-part pouching system }\end{array}$ & ${ }^{*} 0.89$ & ${ }^{*} 1.0$ \\
\hline $\begin{array}{l}\text { Regarding the description of the technique of changing } \\
\text { a two-part pouching system }\end{array}$ & ${ }^{*} 0.89$ & ${ }^{*} 1.0$ \\
\hline Regarding dermatitis classification & ${ }^{*} 0.97$ & ${ }^{*} 1.0$ \\
\hline Regarding the description of the causes of dermatitis & ${ }^{*} 0.95$ & ${ }^{*} 1.0$ \\
\hline $\begin{array}{l}\text { Regarding the description of the signs and symptoms of } \\
\text { dermatitis }\end{array}$ & ${ }^{*} 0.89$ & ${ }^{*} 1.0$ \\
\hline Regarding the description of therapeutic approaches & ${ }^{*} 0.92$ & ${ }^{*} 1.0$ \\
\hline Global Content Validity Index (g-CVI) & ${ }^{* * *} 0.91$ & ${ }^{* *} 1.0$ \\
\hline
\end{tabular}

Abbreviation: $\mathrm{CVI}$, content validity index.

Content validity index. *Significance $\mathrm{g}-\mathrm{CVI}>0.78$.

Content validity index. ${ }^{* *}$ Significance $\mathrm{g}-\mathrm{CVI}>0.90$. 


\section{THE PERIESTOMAL SKIN}

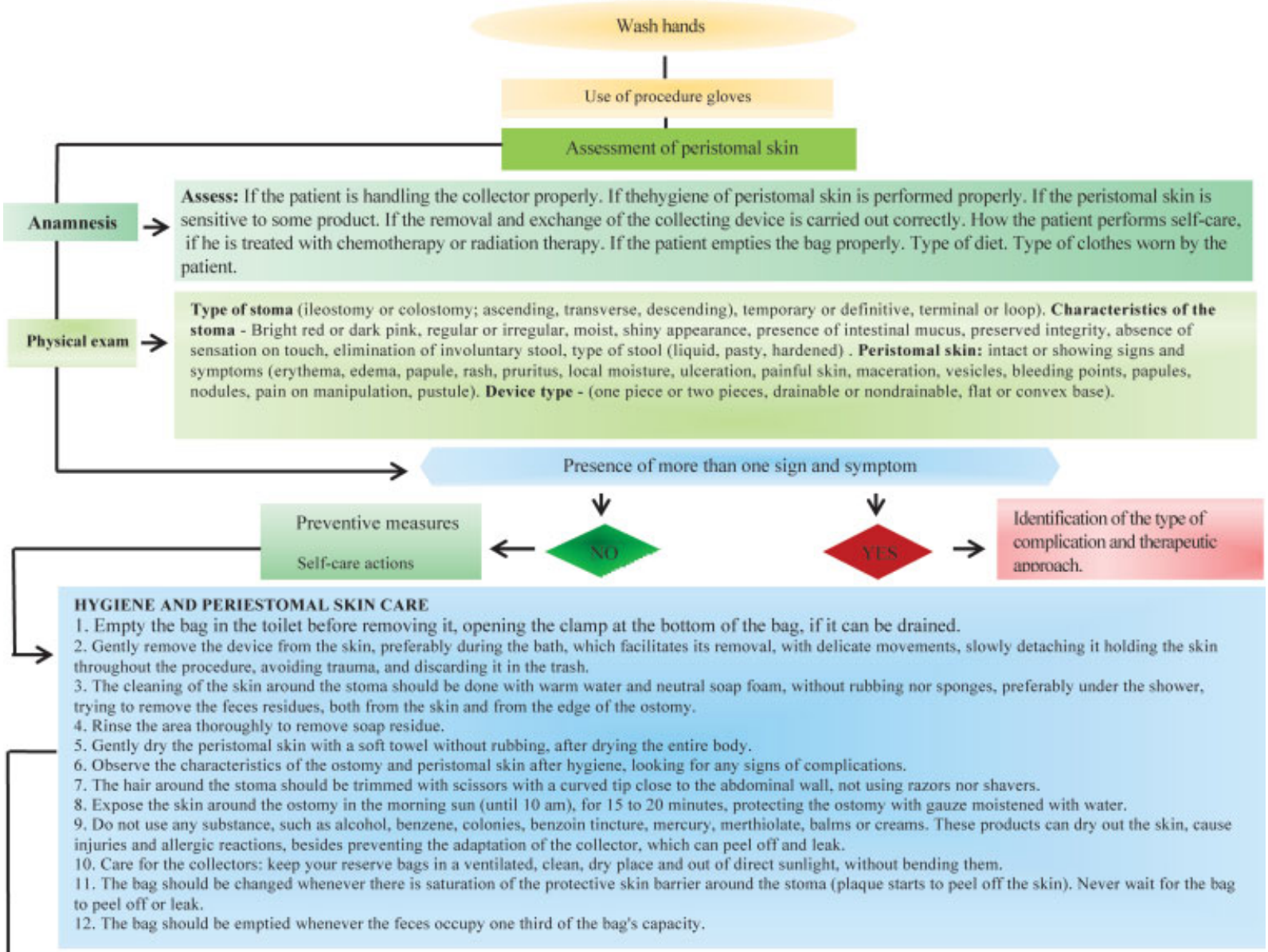

\section{HOW TO CHANGE ONE-PIECE POUCHING SYSTEM.}

1. After following the hygiene and care steps for peristomal skin, measure the size (diameter) of the ostomy with the measurement guide and draw on the adhesive base of the bag.re

2. Cut out the adhesive plate according to the measurement. If it is a pre-cut pouch, choose one that has the orifice the size of the stoma measurement. If it is a cut-out bag, cut the adhesive part with scissors, preferably curved, according to the measured size. Move the plastic part of the pouch away from the adhesive plate, avoiding accidental cutting of the plastic when cutting the plate. The cutout of the plate must not exceed $3 \mathrm{~mm}$ between the stoma and the adhesive plate of the collection bag in order to avoid the contact of feces with the peristomal skin.

3. Remove the paper that protects the barrier.

4. Adjust the plate on the ostomy, holding it by the edge of the barrier or microporous adhesive, if any. Adapt the plate from the bottom to the top, trying to fit it in the ostomy, from the center to the end, without leaving folds or air bubbles. If it is a non-drainable device, remove all air from the bag when adjusting it.

5. Apply gentle pressure on the barrier plate to better adhere to the skin. Make sure that the plate is well adapted to the skin, changing position, seated, lying and standing, in order to check the adaptation of the plate to the skin.

6. The drainable part of the bag must be facing the feet (in patients who are walking) or facing the flank on the same side of the ostomy or diagonally (in bedridden patients).

7. Remove the paper that protects the microporous adhesive, if any, and apply light pressure on it to better adhere to the skin.

8. Remove air from inside the bag and close with the clamp, if it is a drainable device.

9. If you wear a belt, put it on after all these steps.

\section{HOW TO CHANGE THE TWO-PIECE POUCHING SYSTEM.}

1. After following the hygiene and care steps for peristomal skin, measure the size (diameter) of the stoma with the measurement guide and draw on the adhesive base of the bay.

2. Cut out the adhesive plate according to the measurement. If it is a pre-cut pouch, choose the one with the orifice the size of the stoma measurement. If it is a cut-out bag, cut the adhesive part with scissors, preferably curved, according to the measured size.

3. Remove the paper that protects the barrier.

4. Adjust the plate on the ostomy, holding it by the edge of the barrier or microporous adhesive, if any. Adapt the plate from the bottom to the top, trying to fit it in the ostomy, from the center to the end, without leaving folds or air bubbles. Apply gentle pressure on the barrier plate to better adhere to the skin. Make sure that the plate is well adapted to the skin, changing position, seated, lying and standing, in order to check the adaptation of the plate to the skin.

5. Fit the bag over the flange of the plate, holding it by the tab with the opening facing the feet (in patients who are walking) or facing the flank on the same side of the stoma or diagonally (in bedridden patients). If the coupling system is self-adhesive. attach the two parts with adhesive.

6. Apply pressure to the collecting bag rim and the plate flange. On the floating flange, place your fingers under it and your thumbs on the rim of the bag to finish fitting the bag to the plate.

7. Remove the paper that protects the microporous adhesive, if any, and apply light pressure on it to better adhere to the skin.

8. Remove air from inside the bag and close with the clamp if it is a drainable device.

9. If you wear a belt, put it on after all these steps.

10. As it is two pieces, you can remove the bag to wash if necessary, with water and liquid soap, dry and use the same bag again, or use the spare bag, without the need to change the adhesive plate, if it is still in good shape for use.

Fig. 1 Algorithm for the Prevention of Peristomal Skin Complications. Pouso Alegre, MG, Brasil, 2019. 


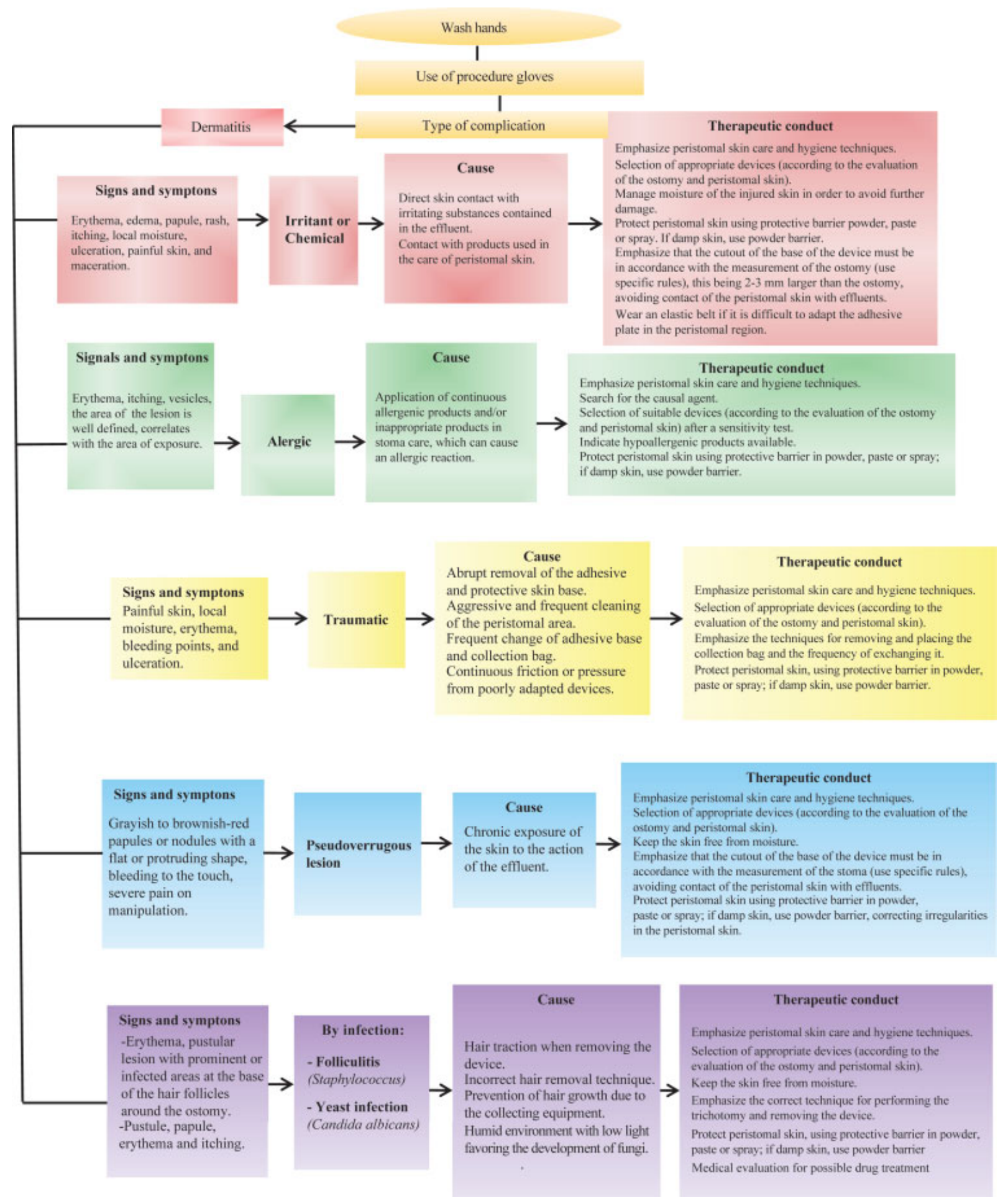

Fig. 2 Algorithm for the Treatment of Peristomal Skin Complications. Pouso Alegre, MG, Brasil, 2019.

results in a better quality of life for the patients. Algorithms are modern ways of information that contribute to future advances in the provision of work content, as well as protocols and palliative care.

Therefore, concluding, it is possible to affirm that after an integrative literature review, the algorithms were built and validated by professionals with experience in the area, showing $100 \%$ agreement among the experts in the second evaluation.

\section{Conflict of Interests}

The authors have no conflict of interests to declare.

\section{References}

1 Lenza NFB, Sonobe HM, Buetto LS, Santos MG, Lima MS. O ensino do autocuidado aos pacientes estomizados e seus familiares: uma revisão integrativa. Rev Bras Promoç Saúde 2013;26(01): $139-145$ 
2 Santos AC, Dutra RAA, Salomé GM, Ferreira LM. Construction and internal reliability of an algorithm for choice cleaning and topical therapy on wounds. J Nurs UFPE online 2018;12(05): 680-85

3 Instituto Brasileiro de Geografia e Estatística. https://www.ibge. gov.br/calendario-de-divulgacoes-novoportal.html2010. [cited June $\left.9^{\text {th }}, 2019\right]$.

4 Soares CS, Santos I, Berardinelli LMM. Obesity as a social problem: identifying guidance needs of nursing for self-care. Rev Enferm UFPE on line 2010;4(01):18-27. Doi: 10.5205/reuol.520-5592-3LE.0401201003

5 Salome GM, Almeida SA. Association of sociodemographic and clinical factors with the self-image and self-esteem of individuals with intestinal stoma. J Coloproctol 2014;4(03):159-66

6 Salomé GM, Almeida SA, Mendes B, Carvalho MRF, Massahud. Assessment of subjective well-being and quality of life in patients with intestinal stoma. J Coloproctol 2015;35(03):168-174. Doi: 10.1016/j.jcol.2015.03.002

7 Lima JA, Muniz KC, Salomé GM, Ferreira LM. Association of sociodemographic and clinical factors with self-image, self-esteem and locus of health control in patients with an intestinal stoma. J Coloproctol 2018;38(01):56-64. Doi: 10.1016/j.jcol.2017.11.003

8 Moreira CNO, Marques CB, Salomé GM, Cunha DR, Pinheiro FAM. Health locus of control, spirituality and hope for healing in individuals with intestinal stoma. J Coloproct 2016;36(04): 208-215. Doi: 10.1016/j.jcol.2016.04.013

9 Perissotto S, Breder JSC, Zulian LR, de Oliveira VX, da Silveira NI, Alexandre NMC. Ações de enfermagem para prevenção e tratamento de complicações em estomias intestinais: revisão integrativa. Estima, Braz J Enterostomal Ther 2019;17:e0519. Doi: 10.30886/estima. v17.638_PT

10 Russell S. Exercise after ostomy surgery and peristomal hernia: a view from here. J Wound Ostomy Continence Nurs 2019;46(03): 215-218. Doi: 10.1097/WON.0000000000000521

11 Nunes MLG, Santos VLCG. Instrumentos de avaliação das complicações da pele periestoma: revisão integrativa. Aquichan 2018;18 (02):477-491. Doi: 10.5294/aqui.2018.18.4.9

12 Somayaji R. Delving into skin soft tissue infections (SSTI) part I: an overview of infection. WCET Journal 2016;36(02):29-34. Doi: 10.3316/informit.095716017578970

13 Antonini M, Militello G, Manfredda S, Arena R, Veraldi S. A revised version of the SACS Scale for peristomal skin disorders classification. WCET Journal. 2016;36(03):22-29. Doi: 10.3316/INFORMIT.361794847146066

14 Salomé GM, Carvalho MRF, Massahud MR Junior, Mendes B. Profile of ostomy patients residing in Pouso Alegre city. J Coloproctol 2015;35(02):106-112. Doi: 10.1016/j.jcol.2015.02.002

15 Salomé GM, de Almeida SA, de Jesus Pereira MT, et al. The Impact of Venous Leg Ulcers on Body Image and Self-esteem. Adv Skin Wound Care 2016;29(07):316-321

16 Salomé GM, Santos LF, Cabeceira HS, Panza AMM, Paula MAB. Knowledge of undergraduate nursing course teachers on the prevention and care of peristomal skin. J Coloproctol 2014;34 (04):224-230. Doi: 10.1016/j.jcol.2014.05.008
17 Carvalho MRF, Salomé GM, Ferreira LM. Construção e validação de algoritmo para tratamento da lesão por pressão. Rev Enferm UFPE on line 2017;11(Suppl 10):2533-2540

18 Cunha DRD, Salomé GM, Massahud MR, Mendes B, Ferreira LM. Development and validation of an algorithm for laser application in wound treatment. Rev Lat Am Enfermagem 2017;25:e2955

19 Cunha JB, Dutra RAA, Salomé GM. Elaboration of an algorithm for wound evaluation and treatment. Estima, Braz J Enterostomal Ther 2018;16:e2018. Doi: 10.30886/estima.v16524

20 van Rijswijk L, Beitz JM. Pressure ulcer prevention algorithm content validation: a mixed-methods, quantitative study. Ostomy Wound Manage 2015;61(04):48-57

21 Melnyk BM, Fineout-Overholt E. Evidence-based practice in nursing \& healthcare: a guide to best practice. Philadelphia: Lippincott Williams \& Wilkins; 2005

22 Grant JS, Davis LL. Selection and use of content experts for instrument development. Res Nurs Health 1997;20(03):269-274

23 Cassiani SH, Rodrigues LP. A técnica de Delphi e a técnica de grupo nominal como estratégias de coleta de dados das pesquisas em enfermagem. Acta Paul Enferm 1996;9(3):76-83

24 Brandão ES, Santos I, Lanzillotti RS. Validação de um instrumento para avaliação do cliente com afecções cutâneas. Acta Paul Enferm 2013;26 (05):460-466. Doi: 10.1590/S0103-21002013000500009

25 Wynd CA, Schmidt B, Schaefer MA. Two quantitative approaches for estimating content validity. West J Nurs Res 2003;25(05):508-518

26 Catunda HLO, Bernardo EBR, Vasconcellos CTM, Moura ERF, Pinheiro AKB, Aquino OS. Methodological approach in nursing research for constructing and validating protocols. Texto Contexto Enferm 2017; 26(02):e00650016. Doi: 10.1590/0104-07072017000650016

27 Pott FS, Ribas JD, Silva OBM, et al. Algoritmo de prevenção e tratamento de úlcera por pressão. Cogitare Enferm. 2013;18(02): 23844. Doi: $10.5380 /$ ce.v18i2.26085

28 Galvão EC F, Puschel VA, Galvão ECF, Puschel VAA. A Multimidia application in mobile platform for teaching the measurement of central venous pressure. Rev Esc Enferm USP 2012;46; (n.spe):107-15. Doi: 10.1590/s0080-62342012000700016

29 Gonçalves MB, Rabeb SAN, Nogueira PC. Revisão - Terapia tópica para ferida crônica: recomendações para prática baseada em evidências. Estima [Internet] 2015;12(1):42-49. Available from: https://www.revistaestima.com.br/estima/article/view/337

30 Johnson JJ, Paustrian C. Guideline for management of wounds in patients with lower-extremity venous disease [Internet]. Glenview: Wound Ostomy and Continence Nurses Society-WOCN; 2005. [cited jun 09, 2019]. Available from: http://www.wocn.org/news/67120/ Guideline-for-Management-of-Wounds-in-Patients-withLowerExtremity-Venous-Disease-Available-Now.htm

31 Mendes B, Salomé GM, Pinheiro FAM, Massahud MR Júnior, da Cunha DM, Ferreira LM. Prevention and treatment of the trench foot: validation of a teaching manual for military personnel. J Wound Care 2018;27 (Sup10): S33-S38

32 Salomé GM, Cunho AL, Pereira AP, Miranda FD, Alves JR. Educational handbook for healthcare professionals: Preventing complications and treating peristomal skin. J Coloproctol 2019;39 (04):332-338. Doi: 10.1016/j.jcol.2019.07.005 